\title{
Radiative absorption enhancement of dust mixed with anthropogenic pollution over East Asia
}

\author{
Pengfei Tian ${ }^{1,2}$, Lei Zhang ${ }^{1}$, Jianmin $\mathrm{Ma}^{2,3}$, Kai Tang ${ }^{1}$, Lili Xu ${ }^{1}$, Yuan Wang ${ }^{4}$, Xianjie Cao ${ }^{1}$, Jiening Liang ${ }^{1}$, \\ Yuemeng $\mathrm{Ji}^{5}$, Jonathan H. Jiang ${ }^{6}$, Yuk L. Yung ${ }^{4}$, and Renyi Zhang ${ }^{5}$ \\ ${ }^{1}$ Key Laboratory for Semi-Arid Climate Change of the Ministry of Education, College of Atmospheric Sciences, \\ Lanzhou University, Lanzhou, China \\ ${ }^{2}$ Key Laboratory for Environmental Pollution Prediction and Control, Gansu Province, College of Earth and Environmental \\ Sciences, Lanzhou University, Lanzhou, China \\ ${ }^{3}$ Laboratory for Earth Surface Processes, College of Urban and Environmental Sciences, Peking University, Beijing, China \\ ${ }^{4}$ Division of Geological and Planetary Sciences, California Institute of Technology, Pasadena, CA 91125, USA \\ ${ }^{5}$ Department of Atmospheric Sciences, Texas A\&M University, College Station, TX 77843, USA \\ ${ }^{6}$ Jet Propulsion Laboratory, California Institute of Technology, Pasadena, CA 91125, USA
}

Correspondence: Lei Zhang (zhanglei@lzu.edu.cn) and Yuan Wang (yuan.wang@caltech.edu)

Received: 5 January 2018 - Discussion started: 30 January 2018

Revised: 16 May 2018 - Accepted: 17 May 2018 - Published: 4 June 2018

\begin{abstract}
The particle mixing state plays a significant yet poorly quantified role in aerosol radiative forcing, especially for the mixing of dust (mineral absorbing) and anthropogenic pollution (black carbon absorbing) over East Asia. We have investigated the absorption enhancement of mixed-type aerosols over East Asia by using the Aerosol Robotic Network observations and radiative transfer model calculations. The mixed-type aerosols exhibit significantly enhanced absorbing ability than the corresponding unmixed dust and anthropogenic aerosols, as revealed in the spectral behavior of absorbing aerosol optical depth, single scattering albedo, and imaginary refractive index. The aerosol radiative efficiencies for the dust, mixed-type, and anthropogenic aerosols are $-101.0,-112.9$, and $-98.3 \mathrm{Wm}^{-2} \tau^{-1}$ at the bottom of the atmosphere (BOA); $-42.3,-22.5$, and $-39.8 \mathrm{Wm}^{-2} \tau^{-1}$ at the top of the atmosphere (TOA); and 58.7, 90.3, and 58.5 $\mathrm{Wm}^{-2} \tau^{-1}$ in the atmosphere (ATM), respectively. The BOA cooling and ATM heating efficiencies of the mixed-type aerosols are significantly higher than those of the unmixed aerosol types over the East Asia region, resulting in atmospheric stabilization. In addition, the mixed-type aerosols correspond to a lower TOA cooling efficiency, indicating that the cooling effect by the corresponding individual aerosol components is partially counteracted. We conclude that the interaction between dust and anthro-
\end{abstract}

pogenic pollution not only represents a viable aerosol formation pathway but also results in unfavorable dispersion conditions, both exacerbating the regional air pollution in East Asia. Our results highlight the necessity to accurately account for the mixing state of aerosols in atmospheric models over East Asia in order to better understand the formation mechanism for regional air pollution and to assess its impacts on human health, weather, and climate.

\section{Introduction}

Atmospheric aerosols or particulate matter (PM) profoundly affect the energy budget of the Earth-atmosphere system directly by interfering with the radiative transfer and indirectly by modifying cloud formation (Twomey, 1977; Charlson et al., 1992; Fan et al., 2007; Wang et al., 2011). However, the assessment of the aerosol radiative effects is limited because of the inherent difficulties associated with observations and model simulations (Stevens and Bony, 2013; Kok et al., 2017). In particular, an accurate quantification of the mixing state of absorbing aerosols poses a great challenge in the estimation of the direct aerosol radiative forcing (Haywood and Boucher, 2000; He et al., 2015). Currently, the assessment of the direct and indirect aerosol radiative forcing represents 
large uncertainty in the prediction of future climate by anthropogenic activities (IPCC, 2007, 2013). Moreover, aerosol mixing state significantly affects atmospheric dynamics (Ramanathan and Carmichael, 2008).

Atmospheric aerosols are typically internally and/or externally mixed during their lifetimes (Jacobson, 2001; Zhang and Zhang, 2005; Zhang et al., 2008; Khalizov et al., 2009a; Pagels et al., 2009; Taylor et al., 2015). The East Asian region is experiencing persistent heavy air pollution conditions in the present day (Guo et al., 2014; Zhang et al., 2015; Wang et al., 2016). Black carbon (BC) is a major anthropogenic pollutant in this region that exerts significant environmental and climatic effects because of the strong absorption of solar radiation (Wang et al., 2012; Peng et al., 2016), which is further enhanced by the "Lensing effect" (e.g., Jacobson, 2001; Cui et al., 2016). East Asia is one of the largest dust source regions, second only to the Sahara (Huang et al., 2014, 2015; Tian et al., 2015). As a result, coarse mode dust particles are frequently mixed with anthropogenic pollution along their transport pathway in East Asia (Noh et al., 2012; Logan et al., 2013; Guo et al., 2017; Hara et al., 2017). The potential anthropogenic influence on dust has been investigated close to the dust source regions (Huang et al., 2010; Bi et al., 2017). Lower single scattering albedo (SSA) of mixed dust plumes has been assessed in previous studies (Kim et al., 2005; Khatri et al., 2014). Li et al. (2015) have studied the SSA spectral curvature of the East Asian aerosol mixtures using Aerosol Robotic Network (AERONET) products and model simulations. The observations from a sun-sky radiometer and a lidar have been applied to identify the presence of Asian dust in mixed aerosol plumes at several East Asian monitoring sites (Noh et al., 2017). Those earlier studies on optical properties and radiative effects of the East Asian dust and anthropogenic aerosol mixtures have promised reduction of the uncertainties in estimating the aerosol radiative effects.

Internal mixing of coarse mode dust with fine mode anthropogenic aerosols has been suggested by observations in the Asian Aerosol Characterization Experiment (ACE-Asia) (Seinfeld et al., 2004) and recent studies (Sugimoto et al., 2015; Wang et al., 2017), although the mechanism leading to the mixing has yet to be elucidated. Internal mixing of dust with anthropogenic pollution likely occurs via condensation of low-volatility organic and inorganic compounds, particle-phase reactions, and coagulation with other aerosol types (Zhang et al., 1996; Zhao et al., 2006; Qiu et al., 2011). In addition, dust particles provide reactive surfaces for catalytic conversion of sulfur dioxide to sulfate, which has been suggested as a key mechanism for severe haze formation in China (Zhang et al., 2015; G. Li et al., 2017). Atmospheric measurements using electron microscopy have identified BC and certain soluble aerosols on the surface of dust particles (Tobo et al., 2010; Ma et al., 2012; Li et al., 2014). Pan et al. (2017) have studied the morphology change of East Asian dust mixed with anthropogenic aerosols and showed the pos- sibility evidence for the occurrence of aqueous-phase reactions.

The aerosol mixing state significantly affects the radiative effects (Jacobson, 2001; Khalizov et al., 2009b; Xue et al., 2009). Several previous studies have shown that the amount of solar radiation reaching the Earth surface through mixtures of mineral dust and other absorbing aerosols is considerably reduced compared to that through dust-only aerosols (Derimian et al., 2008; Obregón et al., 2015). Researchers have reported that the radiative efficiency of non-dust aerosols is higher than that of dust aerosols at two urban Asian cities of Gwangju and Beijing (Noh et al., 2012; Yu et al., 2016). Maximum radiative efficiency under unpolluted conditions has been found by comparing aerosol radiative effects under pristine and polluted conditions (Chen et al., 2016). Aerosol radiative efficiency has been found to be strongly influenced by aerosol absorbing ability (e.g., SSA) and size of fine mode particles in central China (Zhang et al., 2017).

Although the mixing state of dust and anthropogenic aerosols considerably affects aerosol radiative effects, further studies are urgently required to better understand the key role that the East Asian aerosol mixtures play in the formation mechanism of regional air pollution. In this present work, we have extensively investigated the radiative absorption enhancement by the East Asian aerosol mixtures on the basis of long-term AERONET observations and Santa Barbara DISORT Atmospheric Radiative Transfer (SBDART) model simulations. We classified the dust, mixed-type, and anthropogenic aerosols according to the aerosol SSA spectral behavior and Ångström exponent parameter. The optical and microphysical properties of the various aerosol types were analyzed, with emphasis on the absorption enhancement by mixed-type aerosols. The mechanism leading to the radiative absorption enhancement by the mixed-type aerosols and their impacts on regional air pollution and climate have been discussed. Our results suggest that the East Asian aerosol mixtures result in a more stable atmosphere that is unfavorable for diffusion and dispersion of the atmospheric pollutants.

\section{Data and methodology}

\subsection{AERONET data}

The aerosol optical and microphysical data used in this research were originally from AERONET (Holben et al., 1998). To ensure the data quality, we only analyzed the cloud-screened, quality-assured Level 2.0 inversion data. We further constrained the data with solar zenith angle between 50 and $80^{\circ}$ to avoid possible inversion errors and surface albedo smaller than 0.5 to exclude seasonal snow-covered surfaces. The AERONET spectral products are available at the wavelengths of $440,675,870$, and $1020 \mathrm{~nm}$. Previously, Dubovik and King (2000) have evaluated the uncertainty of the AERONET products. 
All available worldwide measurement sites from the AERONET program with a sample number of greater than 100 were included in the present work. Considering the regional representativeness and data availability, 11 sites (Table S1 and Fig. S1 in the Supplement) were selected to represent the various types of the East Asian aerosol mixtures. For example, the sample numbers of Beijing and Xianghe were randomly reduced to a one-fourth of the total numbers because these two sites are close to each other and the total sample numbers of the two sites are significantly larger than the others.

\subsection{Radiative forcing and efficiency calculations}

The direct aerosol radiative forcing $(\Delta F)$ is defined as follows:

$$
\Delta F=\left(F^{\downarrow}-F^{\uparrow}\right)-\left(F_{0}^{\downarrow}-F_{0}^{\uparrow}\right),
$$

where $F$ and $F_{0}$ are radiative fluxes under the aerosolfree and aerosol-laden conditions, respectively, the upward and downward arrows denote the directions of the radiative fluxes. The AERONET products include the aerosol radiative forcing and efficiency, in addition to the optical and microphysical parameters. However, the radiative forcing in the AERONET products was not exactly calculated using Eq. (1). Instead, we calculated the direct aerosol radiative forcing and efficiency by using the widely adopted SBDART model (Ricchiazzi et al., 1998). The aerosol radiative efficiency $\left(\Delta F^{\text {eff }}\right)$ is defined as the direct aerosol radiative forcing per unit aerosol optical depth (AOD):

$\Delta F^{\mathrm{eff}}=\Delta F / \mathrm{AOD}_{0.55}$,

where $\mathrm{AOD}_{0.55}$ is the $550 \mathrm{~nm}$ AOD. However, the direct aerosol radiative forcing is not linearly dependent on AOD (e.g., Wu et al., 2015). To exclude possible errors from aerosol loading in calculating the aerosol radiative efficiency in Eq. (2), the $550 \mathrm{~nm}$ AOD was set to unity $\left(\mathrm{AOD}_{0.55}=1.0\right)$ in SBDART model calculations. The data processing procedure is presented in Fig. 1 and a detailed discussion of aerosol radiative forcing and efficiency calculation has been provided elsewhere (Tian et al., 2018).

\subsection{Aerosol classification}

The SSA spectral behavior and the Ångström exponent parameter were applied to identify aerosol mixtures (Fig. 1). The main absorbing component of the anthropogenic pollutants is BC, which exhibits strong absorption throughout a broad wavelength range (Bond and Bergstrom, 2006). Dust aerosols are also an absorbing medium because of the ironbearing minerals such as hematite, goethite, and magnetite, which enable the dust aerosols to absorb strongly in the UV and short visible wavelengths and weakly in the nearinfrared (Schuster et al., 2016). Thus, the dust aerosols exhibit a monotonically increasing SSA trend with increasing

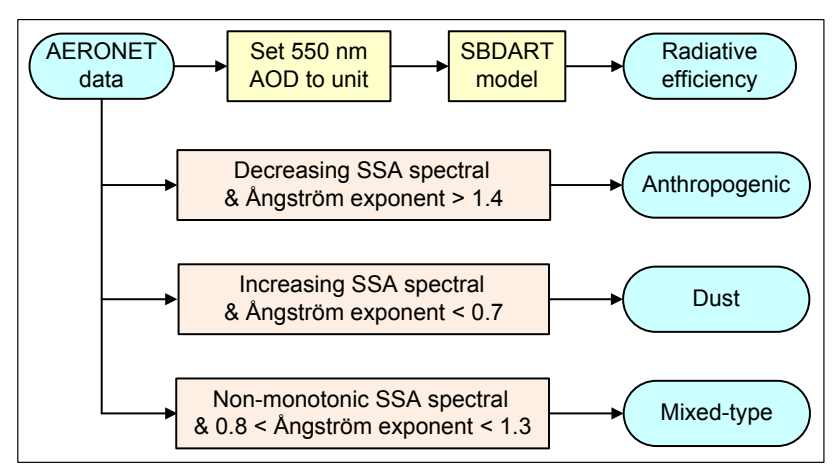

Figure 1. Diagram of the radiative efficiency calculation and aerosol classification.

wavelength, while the anthropogenic pollutants (the absorption of which is mainly contributed by BC) show a monotonically decreasing SSA spectra (Bergstrom et al., 2007; Giles et al., 2012; Tian et al., 2017). The absorption of aerosol mixtures is contributed by both dust and BC, leading to a nonmonotonic SSA spectra (Khatri et al., 2014). The characteristic non-monotonic SSA spectral behavior of mixed-type aerosols provides a useful approach to identify the mixedtype aerosols. SSA curvature of greater than 0.1 , which has been suggested for "moderate mixing" (Li et al., 2015), was applied for the mixed-type aerosol. We employed an additional criterion, Angström exponent, which is related to the aerosol size and the widely used in aerosol classification (Eck et al., 2010; Derimian et al., 2016), to further constrain the aerosol classification. Results show that Ångström exponent values are smaller for coarse mode dust aerosols (lower than 0.7 in the present study), larger for fine mode anthropogenic aerosols (greater than 1.4 in this research), and range from 0.8 and 1.3 for the mixed-type aerosols, respectively.

The imaginary refractive index at $440 \mathrm{~nm}\left(k_{440}\right.$, in the visible bands) versus the average of the imaginary refractive indices at 675,870 , and $1020 \mathrm{~nm}\left(k_{\text {rnir }}\right.$, in the red and nearinfrared bands) is shown in Fig. 2. Anthropogenic aerosols with the absorption mainly contributed by BC particles exhibit a flat imaginary refractive index (Bond and Bergstrom, 2006), while dust with the components such as hematite absorbs strongly in UV but weakly in longer wavelengths (Hsu and Matijević, 1985; Schuster et al., 2016). Hence, the data of anthropogenic aerosols are scattered along the $1: 1$ line (Fig. 2). Dust aerosols show stronger absorption at the visible wavelength than at the red and near-infrared wavelengths, so the data are scattered above the $1: 1$ line. The data for most of the mixed-type aerosols lie above the $1: 1$ line and on the right side of the $k_{\mathrm{rnir}}=0.0042$ threshold, which is suggested by Schuster et al. (2016) to separate dust $\left(k_{\text {rnir }}<0.0042\right)$ and biomass burning $\left(k_{\text {rnir }}>0.0042\right)$ aerosols. The mixed-type aerosols show the strongest absorption and most of the sites with a mixed-type aerosol sample number of 50 and higher 


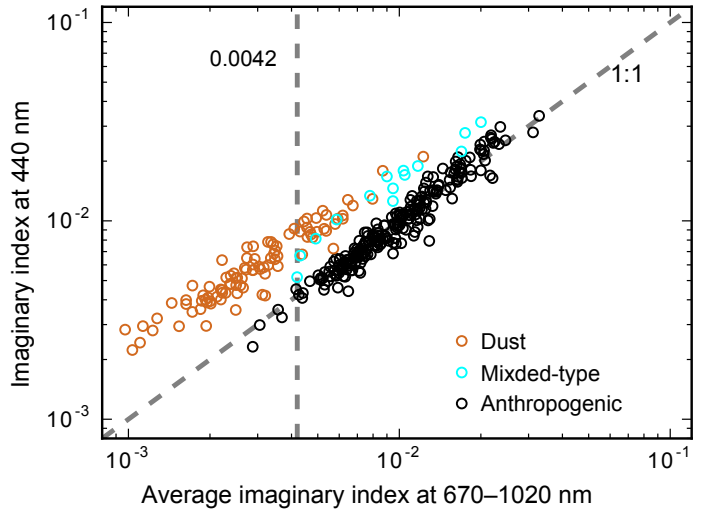

Figure 2. The imaginary refractive index at $440 \mathrm{~nm}$ versus the average of the imaginary refractive indices at 675,870 , and $1020 \mathrm{~nm}$ for dust, mixed-type, and anthropogenic aerosols over worldwide AERONET sites. Only those sites with a sample number of 50 and higher were averaged and shown in the figure.

are located in East Asia. Hence, our method quantitatively separated various aerosol types.

\section{Spectral behavior of the East Asian aerosol mixtures}

Extensive investigations of the spectral optical properties were carried out to discuss the enhanced absorbing ability of the East Asian aerosol mixtures. Dust aerosols show the highest spectral AOD and the anthropogenic aerosols exhibit the lowest spectral AOD (Fig. 3a). The spectral dependence of dust aerosols is nearly invariant across the wavelength spectrum while the dependence of anthropogenic aerosols is relatively high, which is relevant to aerosol size and the Ångström parameter (Ångström, 1929). The mixed-type aerosols have smaller AOD than dust aerosols, but higher absorption aerosol optical depth (AAOD) throughout the wavelength band of 440 to $1020 \mathrm{~nm}$ (Fig. 3b). Dust aerosols exhibit higher AAOD at the $440 \mathrm{~nm}$ wavelength than that of anthropogenic aerosols.

As expected by using our SSA spectral classification method, dust aerosols show a monotonic increasing SSA trend with increasing wavelength, while anthropogenic aerosols exhibit an opposite trend. In contrast, the SSA of the mixed-type aerosols peaks at the wavelength of $675 \mathrm{~nm}$ (Fig. 3c). Interestingly, the mixed-type aerosols exhibit the lowest SSA value that cannot be predicted by our classification method because the classification method considers the spectral trend rather than the value of SSA. This indicates enhanced absorption for the mixed-type aerosols. The spectral average SSA of the dust, mixed-type, and anthropogenic aerosols are 0.94, 0.89, and 0.93, respectively. Hence, internal mixing of the East Asian aerosol mixtures yields the lowest SSA that is distinct from the corresponding individual aerosol types.
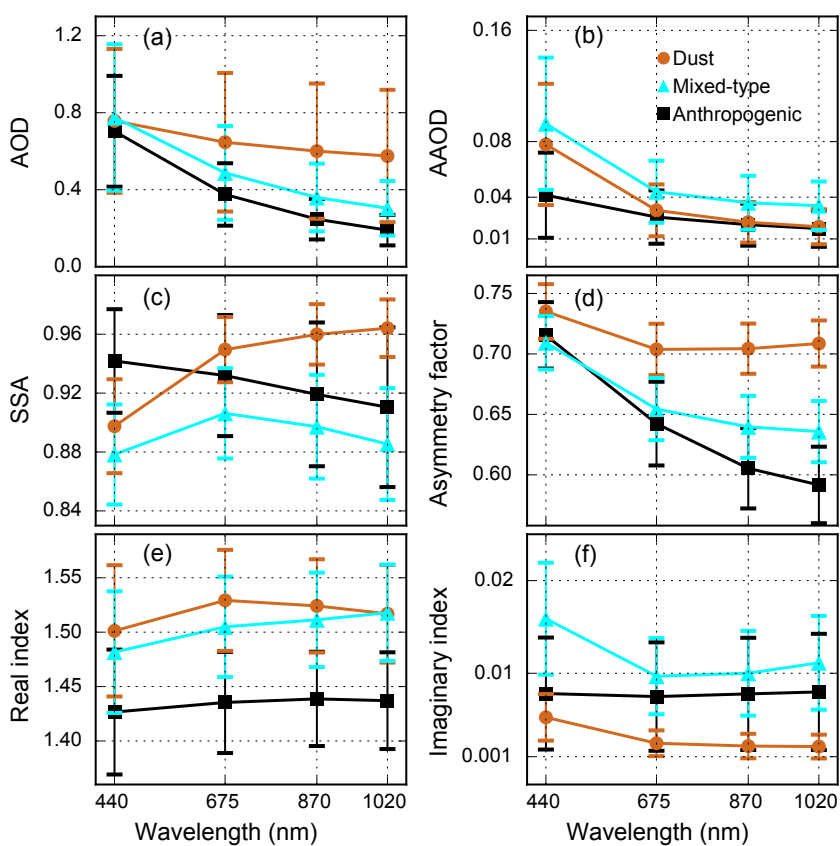

Figure 3. Spectral behavior of (a) AOD, (b) AAOD, (c) SSA, (d) asymmetry factor, (e) real part of the complex refractive index, and (f) imaginary part of the complex refractive index for dust, mixed-type, and anthropogenic aerosols averaged from East Asian sites.

The dust aerosols exhibit the highest value for the real part of the complex refractive index, while the anthropogenic aerosols show the lowest value (Fig. 3e). Interestingly, the real refractive index of the mixed-type aerosols is close to that of dust aerosols, indicating high scattering of the mixedtype aerosols. The spectral imaginary refractive index for anthropogenic aerosols is nearly constant (Fig. 3f), which is characteristic of this aerosol type. However, the imaginary refractive index of anthropogenic aerosols is much lower than that of BC aerosols (approximately 0.6 in Bond and Bergstrom, 2006), because the majority of anthropogenic aerosol components are non-absorbing aerosols such as sulfate and nitrate salts. The spectral imaginary refractive index of dust aerosols is similar to the AERONET dust climatology over Africa and the Middle East (Schuster et al., 2016), with stronger absorption at the visible wavelength $(440 \mathrm{~nm})$. The mixed-type aerosols exhibit the highest imaginary refractive index, especially at the visible wavelength, where the imaginary refractive index of the mixed-type aerosols $(0.0159)$ is more than twice that of anthropogenic aerosols (0.0078).

Hence, the absorbing ability of the East Asian aerosols is significantly enhanced due to the mixing process, in light of the lowest SSA and the highest AAOD and imaginary refractive index for the mixed-type aerosols. 

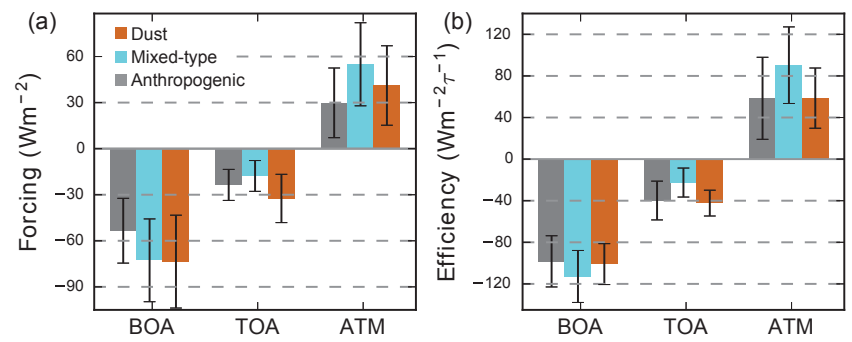

Figure 4. (a) Radiative forcing and (b) radiative efficiency of the dust, mixed-type, and anthropogenic aerosols averaged from East Asian sites.

\section{Enhanced radiative absorption by East Asian aerosol mixtures}

To investigate the radiative effects caused by the enhanced absorbing ability of the East Asian aerosol mixtures, we calculated the average direct aerosol radiative efficiency at the bottom of the atmosphere (BOA), at the top of the atmosphere (TOA), and in the atmosphere (ATM) (Fig. 4), respectively. The mixed-type aerosols exhibit lower spectral average AOD (0.48) than dust aerosols (0.64) (Fig. 3a), but show comparable radiative forcing relative to dust aerosols at BOA $\left(-72.7\right.$ and $-73.6 \mathrm{Wm}^{-2}$ for the mixed-type and dust aerosols, respectively) (Fig. 4a). This feature is explained by higher BOA cooling efficiency of the mixed-type aerosols $\left(-112.9 \mathrm{Wm}^{-2} \tau^{-1}\right)$ than dust $\left(-101.0 \mathrm{Wm}^{-2} \tau^{-1}\right)$ (Fig. 4b). The radiative absorption enhancement is evident for the TOA and ATM forcing: the mixed-type aerosols exhibit the highest ATM radiative forcing $\left(55.0 \mathrm{Wm}^{-2}\right)$ and the lowest absolute TOA forcing $\left(-17.8 \mathrm{Wm}^{-2}\right)$. For comparison, we calculated the aerosol radiative efficiency of various aerosol types to rule out the effect of aerosol loading. The mixed-type aerosols exhibit the highest BOA cooling efficiency, the highest ATM heating efficiency $\left(90.3 \mathrm{Wm}^{-2} \tau^{-1}\right)$, and the lowest TOA cooling efficiency $\left(-22.5 \mathrm{Wm}^{-2} \tau^{-1}\right)$.

The average BOA radiative efficiency of dust aerosols $\left(-101.0 \mathrm{Wm}^{-2} \tau^{-1}\right)$ in the present study (Fig. $\left.4 \mathrm{~b}\right)$ falls in the range of -96.1 to $-127.0 \mathrm{Wm}^{-2} \tau^{-1}$ by Yu et al. (2016), but lower than the result of $-124.6 \pm 12.2 \mathrm{Wm}^{-2} \tau^{-1}$ by Noh et al. (2012). Note that results by Noh et al. (2012) and Yu et al. (2016) are likely biased due to a non-linear dependence between direct aerosol radiative forcing and AOD, which is avoided in the present study. Our previous work (Tian et al., 2018), which used the same radiative efficiency calculation method but a different aerosol classification approach from the present study, obtained a similar BOA radiative efficiency of $-102.3 \mathrm{Wm}^{-2} \tau^{-1}$ at the Semi-Arid Climate and Environment Observatory of Lanzhou University (SACOL), northwestern China.

The spatial distributions of the aerosol radiative efficiency for BOA, ATM, and TOA are presented in Figs. 5-7, respec-

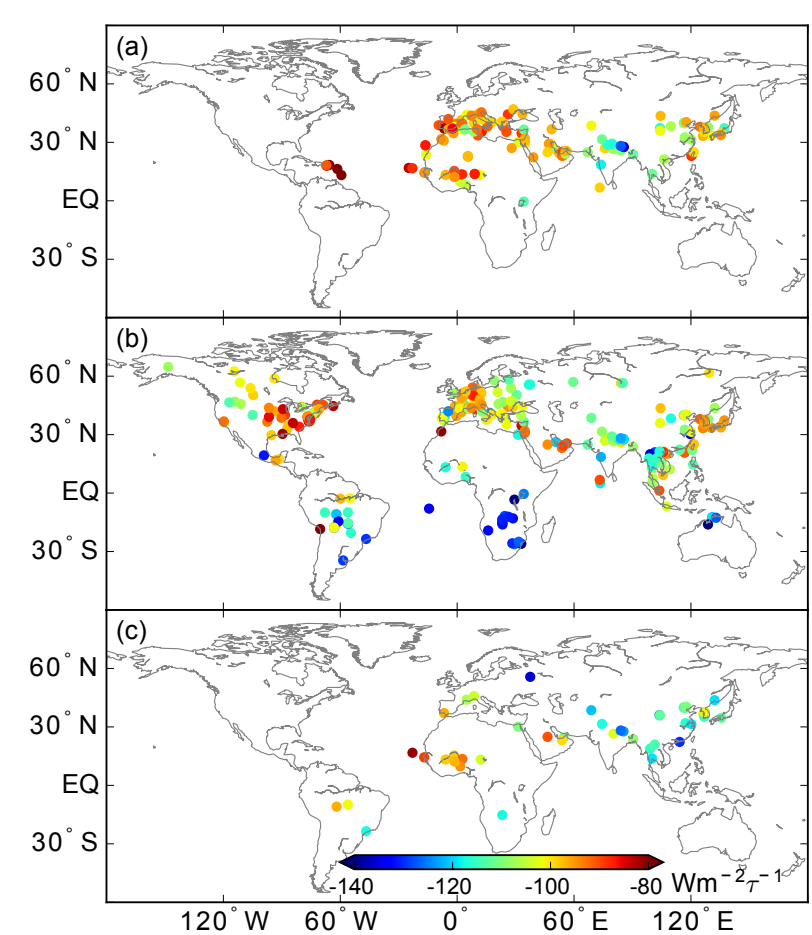

Figure 5. Aerosol radiative efficiency at BOA: (a) dust aerosols, (b) anthropogenic aerosols, and (c) mixed-type aerosols.

tively. Only those sites with a sample number of greater than 50 were averaged and included in the figures. Despite the fact that AERONET sites are unavailable in some remote areas, the worldwide aerosol distributions are well captured by the AERONET observations. The mixed-type aerosols are distributed in East Asia, India, and around Saharan regions.

The mixed-type aerosols exhibit a higher BOA radiative cooling efficiency than that of dust and anthropogenic aerosols over the East Asia region (Fig. 5). The BOA radiative cooling efficiency over India is also high, but the difference of various aerosol types is small. Biomass burning aerosols over Africa exhibit the highest BOA cooling efficiency in the globe, which may be explained by the different combustion compositions and processes as described in Eck et al. (2010) and García et al. (2012). Anthropogenic aerosols over North America and dust aerosols around the Sahara show a relatively lower BOA cooling efficiency.

The mixed-type aerosols also exhibit a higher ATM radiative heating efficiency than dust and anthropogenic aerosols over East Asia (Fig. 6). The ATM radiative heating efficiency over India is high for all aerosol types. The ATM radiative heating efficiency is high over South Africa, where biomass burning aerosols dominate. In contrast, the ATM radiative heating efficiency over North America and around the Saharan regions is relatively smaller.

The enhanced BOA cooling and ATM heating efficiencies reveal that the mixed-type aerosols exhibit higher BOA cooling and ATM heating effects than those of the unmixed dust 


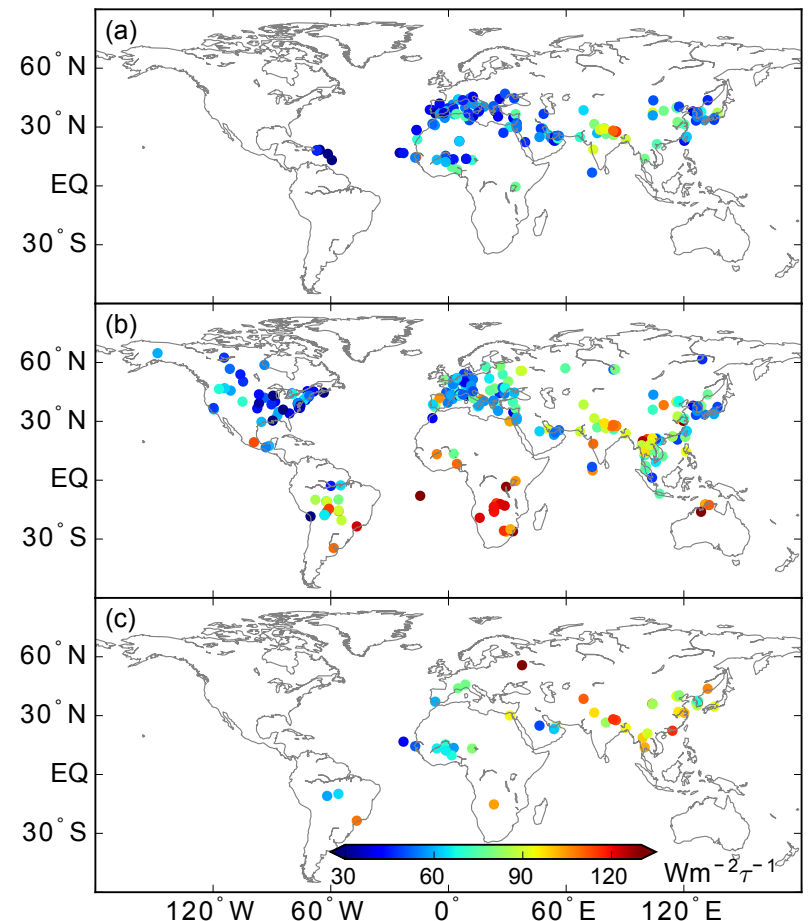

Figure 6. Aerosol radiative efficiency in ATM: (a) dust aerosols, (b) anthropogenic aerosols, and (c) mixed-type aerosols.

and anthropogenic aerosols with the same aerosol loading. The enhanced BOA cooling and ATM heating effects lead to a cooler surface and warmer atmosphere and restrain the development of the planetary boundary layer, resulting in a more stable atmosphere that is unfavorable for dispersion of atmospheric gaseous and PM pollutants. Noting that mixedtype aerosols occur frequently in East Asia and their occurrence can reach as high as $50 \%$ over some locations ( $\mathrm{Li}$ et al., 2015). Hence, the mixed-type aerosols likely play a significant role in enhancing air pollution over East Asia. In addition, the mixed-type aerosols show lower TOA radiative cooling efficiency than dust and anthropogenic aerosols over the East Asia region (Fig. S1). The reduced TOA cooling efficiency indicates that the East Asian aerosol mixtures partially counteract the cooling effect of the Earth-atmosphere system by the corresponding individual components.

\section{Discussions}

The direct aerosol radiative efficiency strongly depends on solar zenith angle (e.g., Derimian et al., 2016). To investigate the influence of solar zenith angle on the result of the present study, the aerosol radiative efficiency as a function of solar zenith angle were calculated for various aerosol types (Fig. 7). Note that the AERONET data used in the present study are only available between 50 and $80^{\circ}$ solar zenith angles. The BOA radiative cooling and ATM heating efficiencies (absolute value of radiative efficiency) decrease with increasing solar zenith angle (decreasing cosine of solar zenith angle), while the TOA cooling efficiency increase with increasing solar zenith angle. The mixed-type aerosols exhibit higher BOA cooling efficiency, higher ATM heating efficiency, and lower TOA cooing efficiency than those of unmixed dust and anthropogenic aerosols. The dust aerosols exhibit both higher BOA and TOA cooling efficiency than the anthropogenic aerosols, leading to small difference in the ATM heating efficiency between the two aerosol types.

Aerosol absorption has been suggested as a key factor that determines the aerosol radiative effects ( $\mathrm{Li}$ et al., 2010). The aerosol radiative efficiencies as a function of SSA and imaginary refractive index for various aerosol types were calculated to investigate the effect of aerosol absorbing on the aerosols radiative efficiency (Figs. 8 and 9). The BOA cooling efficiency and ATM heating efficiency increase with increasing absorption (i.e., decreasing SSA and increasing imaginary refractive index) and the TOA cooling efficiency decrease with increasing absorption. However, the dependences between radiative efficiency and SSA are stronger than those between radiative efficiency and the imaginary refractive index for BOA, TOA, and ATM. The dependences between radiative efficiency and SSA are approximately linear, but the dependences between radiative efficiency and imaginary refractive index become less apparent with increasing imaginary refractive index. The strong dependence between aerosol radiative efficiency and SSA has also been shown over central China and desert and semi-desert regions of northwestern China (Xin et al., 2016; Zhang et al., 2017).

We also examined the effects of the fraction of fine and coarse mode on aerosol radiative efficiency (Fig. 10). The BOA cooling and ATM heating efficiencies (TOA cooling efficiency) initially increase (decreases) with increasing fine mode fraction (FMF), when FMF is lower than 0.3 and coarse mode dust aerosols dominate. Then the BOA cooling and ATM heating efficiencies (TOA cooling efficiency) reach a peak (bottom) in the FMF range of 0.3 to 0.5 . Finally the BOA cooling and ATM heating efficiency (TOA cooling efficiency) begin to decrease (increase) when FMF is greater than 0.5 , where fine mode anthropogenic aerosols become dominate. Overall, the moderate mixing of dust with fine mode anthropogenic pollutants, which is classified as mixed-type aerosols in the present study, is responsible for the enhanced radiative absorption. A previous study (Li et al., 2015) has revealed that moderate mixing of East Asian dust with fine mode pollutants is responsible for high SSA spectral curvature, which suggests well-mixed aerosol mixtures.

\section{Conclusions}

The mixing state of atmospheric aerosols plays a significant yet poorly quantified role in determining the aerosol 

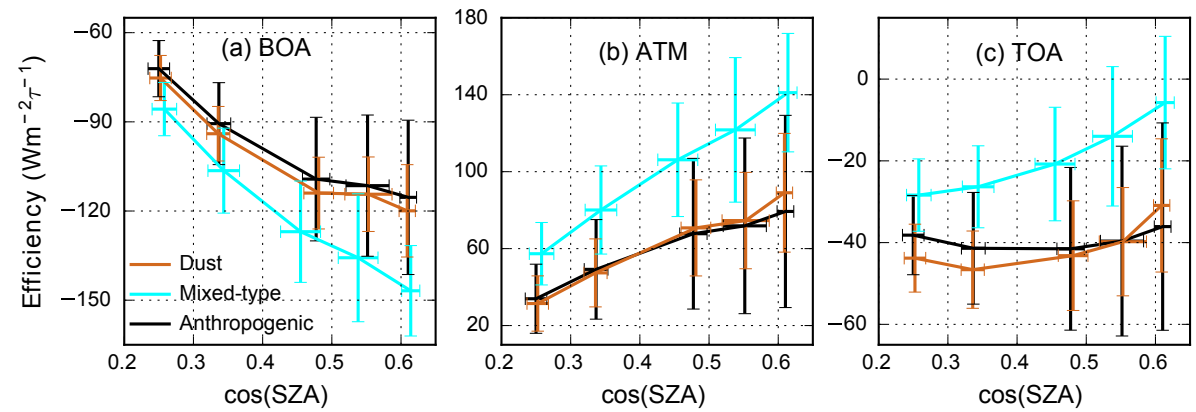

Figure 7. Direct aerosol radiative efficiency as a function of the cosine of solar zenith angle for the dust, mixed-type and anthropogenic aerosols: (a) BOA, (b) ATM, and (c) TOA.
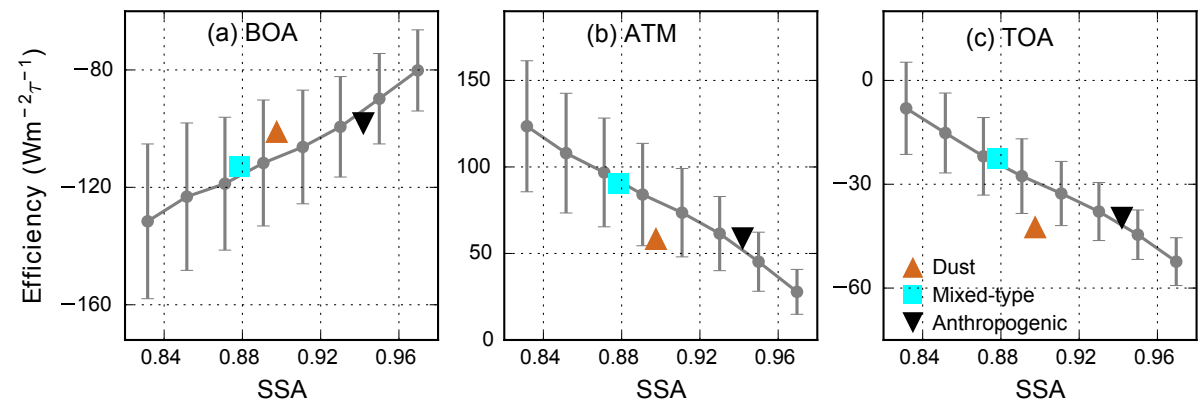

Figure 8. Direct aerosol radiative efficiency as a function of SSA for the dust, mixed-type and anthropogenic aerosols: (a) BOA, (b) ATM, and (c) TOA.

optical properties and radiative effects. In the East Asia region, coarse mode dust and fine mode anthropogenic pollution are typically mixed externally and/or internally in the atmosphere. The mixing of dust with anthropogenic aerosols exerts a significant influence on aerosol absorption and radiative efficiency. We present an extensive investigation of the radiative effects of the East Asian aerosol mixtures.

The mixed-type aerosols exhibit significantly higher AAOD, lower SSA, and higher imaginary refractive index than those of unmixed dust and anthropogenic aerosols, showing significantly enhanced absorption. The absorption enhancement is most evident at wavelength $440 \mathrm{~nm}$, where the imaginary refractive index of the mixed-type aerosols $(0.0159)$ is more than twice that of anthropogenic aerosols (0.0078). The mixed-type aerosols also exhibit a unique nonmonotonic SSA trend, which provides a characteristic signature for identifying these aerosols.

The values of the aerosol radiative efficiencies for dust, mixed-type and anthropogenic aerosols are -101.0 , -112.9 , and $-98.3 \mathrm{Wm}^{-2} \tau^{-1}$ for $\mathrm{BOA} ;-42.3,-22.5$, and $-39.8 \mathrm{Wm}^{-2} \tau^{-1}$ for TOA; and 58.7, 90.3, and $58.5 \mathrm{Wm}^{-2} \tau^{-1}$ for ATM, respectively. The mixed-type aerosols exhibit significantly higher BOA radiative cooling efficiency and ATM heating efficiency than those of dust and anthropogenic aerosols over East Asia. These enhanced BOA cooling and ATM heating efficiencies reveal that the mixedtype aerosols exhibit stronger BOA cooling and ATM heat- ing effects than those of unmixed dust and anthropogenic aerosols for a given aerosol loading, resulting in a more stable atmosphere that is unfavorable for the diffusion and dispersion of the gaseous and PM pollution. Hence, our results suggest that the mixed-type aerosols likely play a significant role in enhancing the air pollution in East Asia, because the mixing of dust and anthropogenic aerosols occurs frequently in this region. In addition, the mixed-type aerosols show lower TOA cooling efficiency, indicating that the mixed-type aerosols partially counteract the cooling effect of the Earthatmosphere system by the corresponding individual components. Since dust particles play a catalytic role in the conversion of sulfur dioxide to sulfate (Zhang et al., 2015; G. Li et al., 2017), the interaction between dust and anthropogenic aerosols also provides a possible mechanism for the observed efficient internal mixing and enhanced radiative absorption over East Asia.

Multiple factors have been suggested to be responsible for severe air pollution in East Asia, including the interaction between $\mathrm{BC}$ aerosols and the atmospheric boundary layer (Ding et al., 2016; Peng et al., 2016; Z. Li et al., 2017), rapid secondary aerosol formation during severe haze events (Wang et al., 2016), weakening of the East Asian monsoon circulation (Wu et al., 2016), and climate change (Cai et al, 2017). Our results indicate that interaction between dust and anthropogenic pollution not only represents a plausible pathway for PM formation and internal mixing but also results in unfavor- 

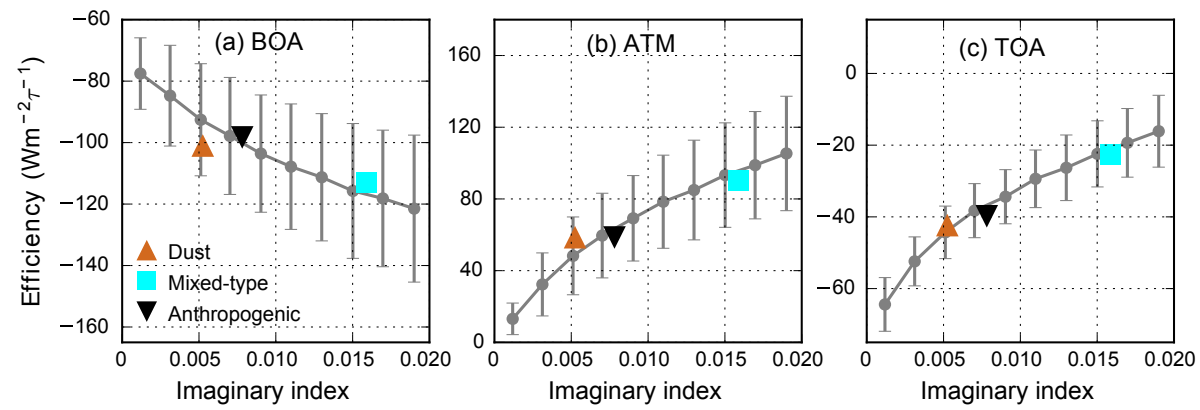

Figure 9. Direct aerosol radiative efficiency as a function of imaginary refractive index for the dust, mixed-type, and anthropogenic aerosols: (a) BOA, (b) ATM, and (c) TOA.
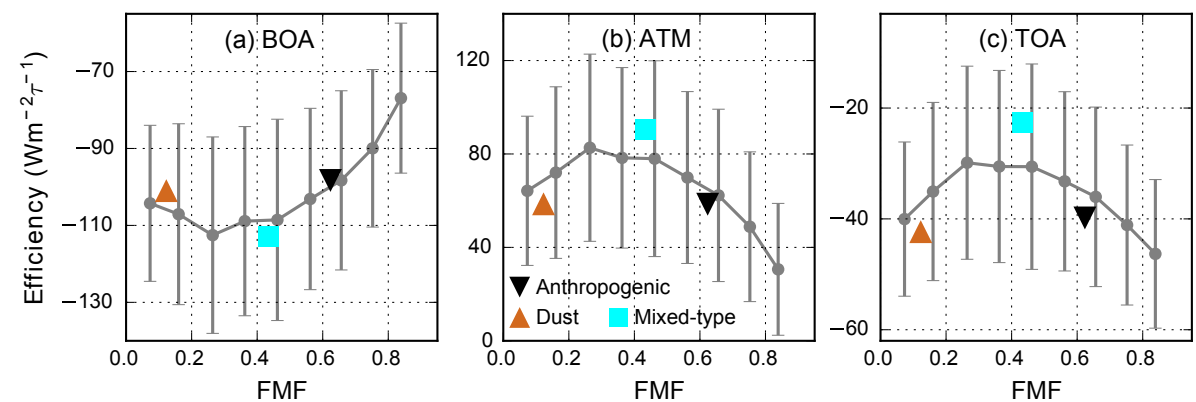

Figure 10. Direct aerosol radiative efficiency as a function of FMF in the East Asian region: (a) BOA, (b) ATM, and (c) TOA. The average radiative efficiencies of the dust, mixed-type, and anthropogenic aerosols are also plotted.

able dispersion conditions (i.e., increased atmospheric stability), both exacerbating regional air pollution in East Asia. Clearly, future studies are necessary to more accurately assess the mixing state of aerosols in atmospheric models in order to better understand the formation mechanism for air pollution over East Asian and to assess its impacts on human heath, weather, and climate (Zhang et al., 2015).

Data availability. The original sun photometer data are available from the AERONET website (https://aeronet.gsfc.nasa.gov/cgi-bin/ webtool_opera_v2_inv, last access: 31 May 2018; Holben et al., 1998). The radiative flux data for the worldwide AERONET sites calculated using the SBDART model and all data for the figures and table in this research are available from the authors upon request.

Supplement. The supplement related to this article is available online at: https://doi.org/10.5194/acp-18-7815-2018-supplement.

Competing interests. The authors declare that they have no conflict of interest.
Special issue statement. This article is part of the special issue "Regional transport and transformation of air pollution in eastern China". It is not associated with a conference.

Acknowledgements. This research was financially supported by National Natural Science Foundation of China (41627807 and 41475008) and National Key R\&D Program of China (2016YFC0401003). Pengfei Tian was funded by China Postdoctoral Science Foundation (2018M631216). Yuan Wang acknowledged the support from NASA ROSES ACMAP. Yuemeng Ji was financially supported by National Natural Science Foundation of China (41675122) and Science and Technology Program of Guangzhou city (201707010188). The authors thank the principal investigators and staff for establishing and maintaining the AERONET sites used in this research. We thank the Institute for Computational Earth System Science (ICESS), University of California, for providing the SADART model. Yuan Wang, Jonathan H. Jiang, and Yuk L. Yung acknowledge support by the Jet Propulsion Laboratory, California Institute of Technology, under contract with NASA.

Edited by: Zhanqing Li

Reviewed by: three anonymous referees 


\section{References}

Ångström, A.: On the Atmospheric Transmission of Sun Radiation and on Dust in the Air, Geogr. Ann., 11, 156-166, https://doi.org/10.2307/519399, 1929.

Bergstrom, R. W., Pilewskie, P., Russell, P. B., Redemann, J., Bond, T. C., Quinn, P. K., and Sierau, B.: Spectral absorption properties of atmospheric aerosols, Atmos. Chem. Phys., 7, 5937-5943, https://doi.org/10.5194/acp-7-5937-2007, 2007.

Bi, J., Huang, J., Shi, J., Hu, Z., Zhou, T., Zhang, G., Huang, Z., Wang, X., and Jin, H.: Measurement of scattering and absorption properties of dust aerosol in a Gobi farmland region of northwestern China - a potential anthropogenic influence, Atmos. Chem. Phys., 17, 7775-7792, https://doi.org/10.5194/acp17-7775-2017, 2017

Bond, T. C. and Bergstrom, R. W.: Light Absorption by Carbonaceous Particles: An Investigative Review, Aerosol Sci. Tech., 40, 27-67, https://doi.org/10.1080/02786820500421521, 2006.

Cai, W., Li, K., Liao, H., Wang, H., and Wu, L.: Weather conditions conducive to Beijing severe haze more frequent under climate change, Nat. Clim. Change, 7, 257-262, https://doi.org/10.1038/nclimate3249, 2017.

Charlson, R. J., Schwartz, S. E., Hales, J. M., Cess, R. D., Coakley, J. A., Hansen, J. E., and Hofmann, D. J.: Climate Forcing by Anthropogenic Aerosols, Science, 255, 423-430, https://doi.org/10.1126/science.255.5043.423, 1992.

Chen, W., Tang, H., Zhao, H., and Yan, L.: Analysis of Aerosol Properties in Beijing Based on Ground-Based Sun Photometer and Air Quality Monitoring Observations from 2005 to 2014, Remote Sens., 8, 110, https://doi.org/10.3390/rs8020110, 2016.

Cui, X., Wang, X., Yang, L., Chen, B., Chen, J., Andersson, A., and Gustafsson, Ö.: Radiative absorption enhancement from coatings on black carbon aerosols, Sci. Total Environ., 551-552, 51-56, 2016.

Derimian, Y., Léon, J. F., Dubovik, O., Chiapello, I., Tanré, D., Sinyuk, A., Auriol, F., Podvin, T., Brogniez, G., and Holben, B. N.: Radiative properties of aerosol mixture observed during the dry season 2006 over M'Bour, Senegal (African Monsoon Multidisciplinary Analysis campaign), J. Geophys. Res.-Atmos., 113, D00C09, https://doi.org/10.1029/2008JD009904, 2008.

Derimian, Y., Dubovik, O., Huang, X., Lapyonok, T., Litvinov, P., Kostinski, A. B., Dubuisson, P., and Ducos, F.: Comprehensive tool for calculation of radiative fluxes: illustration of shortwave aerosol radiative effect sensitivities to the details in aerosol and underlying surface characteristics, Atmos. Chem. Phys., 16, 5763-5780, https://doi.org/10.5194/acp-16-5763-2016, 2016.

Ding, A. J., Huang, X., Nie, W., Sun, J. N., Kerminen, V. M., Petäjä, T., Su, H., Cheng, Y. F., Yang, X. Q., Wang, M. H., Chi, X. G., Wang, J. P., Virkkula, A., Guo, W. D., Yuan, J., Wang, S. Y., Zhang, R. J., Wu, Y. F., Song, Y., Zhu, T., Zilitinkevich, S., Kulmala, M., and Fu, C. B.: Enhanced haze pollution by black carbon in megacities in China, Geophys. Res. Lett., 43, 2873-2879, https://doi.org/10.1002/2016GL067745, 2016.

Dubovik, O. and King, M. D.: A flexible inversion algorithm for retrieval of aerosol optical properties from Sun and sky radiance measurements, J. Geophys. Res.-Atmos., 105, 20673-20696, https://doi.org/10.1029/2000JD900282, 2000.

Eck, T. F., Holben, B. N., Sinyuk, A., Pinker, R. T., Goloub, P., Chen, H., Chatenet, B., Li, Z., Singh, R. P., Tripathi, S. N., Reid, J. S., Giles, D. M., Dubovik, O., O’Neill, N. T., Smirnov, A.,
Wang, P., and Xia, X.: Climatological aspects of the optical properties of fine/coarse mode aerosol mixtures, J. Geophys. Res.Atmos., 115, D19205, https://doi.org/10.1029/2010JD014002, 2010.

Fan, J., Zhang, R., Li, G., and Tao, W. K.: Effects of aerosols and relative humidity on cumulus clouds, J. Geophys. Res.-Atmos., 112, D14204, https://doi.org/10.1029/2006JD008136, 2007.

García, O. E., Díaz, J. P., Expósito, F. J., Díaz, A. M., Dubovik, O., Derimian, Y., Dubuisson, P., and Roger, J.-C.: Shortwave radiative forcing and efficiency of key aerosol types using AERONET data, Atmos. Chem. Phys., 12, 5129-5145, https://doi.org/10.5194/acp-12-5129-2012, 2012.

Giles, D. M., Holben, B. N., Eck, T. F., Sinyuk, A., Smirnov, A., Slutsker, I., Dickerson, R. R., Thompson, A. M., and Schafer, J. S.: An analysis of AERONET aerosol absorption properties and classifications representative of aerosol source regions, J. Geophys. Res.-Atmos., 117, D17203, https://doi.org/10.1029/2012JD018127, 2012.

Guo, J., Lou, M., Miao, Y., Wang, Y., Zeng, Z., Liu, H., He, J., Xu, H., Wang, F., and Min, M.: Trans-Pacific transport of dust aerosols from East Asia: Insights gained from multiple observations and modeling, Environ. Pollut., 230, 1030-1039, 2017.

Guo, S., Hu, M., Zamora, M. L., Peng, J., Shang, D., Zheng, J., Du, Z., Wu, Z., Shao, M., Zeng, L., Molina, M. J., and Zhang, R.: Elucidating severe urban haze formation in China, P. Natl. Acad. Sci. USA, 111, 17373-17378, https://doi.org/10.1073/pnas.1419604111, 2014.

Hara, Y., Nishizawa, T., Sugimoto, N., Matsui, I., Pan, X., Kobayashi, H., Osada, K., and Uno, I.: Optical properties of mixed aerosol layers over Japan derived with multi-wavelength Mie-Raman lidar system, J. Quant. Spectrosc. Ra., 188, 20-27, 2017.

Haywood, J. and Boucher, O.: Estimates of the direct and indirect radiative forcing due to tropospheric aerosols: A review, Rev. Geophys., 38, 513-543, 2000.

He, C., Liou, K.-N., Takano, Y., Zhang, R., Levy Zamora, M., Yang, P., Li, Q., and Leung, L. R.: Variation of the radiative properties during black carbon aging: theoretical and experimental intercomparison, Atmos. Chem. Phys., 15, 11967-11980, https://doi.org/10.5194/acp-15-11967-2015, 2015.

Holben, B. N., Eck, T. F., Slutsker, I., Tanré, D., Buis, J. P., Setzer, A., Vermote, E., Reagan, J. A., Kaufman, Y. J., Nakajima, T., Lavenu, F., Jankowiak, I., and Smirnov, A.: AERONET - A Federated Instrument Network and Data Archive for Aerosol Characterization, Remote Sens. Environ., 66, 1-16, https://doi.org/10.1016/S0034-4257(98)00031-5, 1998.

Hsu, W. P. and Matijević, E.: Optical properties of monodispersed hematite hydrosols, Appl. Optics, 24, 1623-1630, https://doi.org/10.1364/AO.24.001623, 1985.

Huang, J., Wang, T., Wang, W., Li, Z., and Yan, H.: Climate effects of dust aerosols over East Asian arid and semiarid regions, J. Geophys. Res.-Atmos., 119, 11398-311416, https://doi.org/10.1002/2014JD021796, 2014

Huang, K., Zhuang, G., Li, J., Wang, Q., Sun, Y., Lin, Y., and Fu, J. S.: Mixing of Asian dust with pollution aerosol and the transformation of aerosol components during the dust storm over China in spring 2007, J. Geophys. Res.-Atmos., 115, D00K13, https://doi.org/10.1029/2009JD013145, 2010 
Huang, Z., Huang, J., Hayasaka, T., Wang, S., Zhou, T., and Jin, H.: Short-cut transport path for Asian dust directly to the Arctic: a case study, Environ. Res. Lett., 10, 114018, https://doi.org/10.1088/1748-9326/10/11/114018, 2015.

IPCC: Climate Change 2007: The Physical Science Basis. Contribution of Working Group I to the Fourth Assessment Report of the Intergovernmental Panel on Climate Change, edited by: Solomon, S., Qin, D., Manning, M., Chen, Z., Marquis, M., Averyt, K. B., Tignor, M., and Miller, H. L., Cambridge University Press, Cambridge, United Kingdom and New York, NY, USA, 996 pp., 2007.

IPCC: Climate Change 2013: The Physical Science Basis. Contribution of Working Group I to the Fifth Assessment Report of the Intergovernmental Panel on Climate Change, edited by: Stocker, T. F., Qin, D., Plattner, G.-K., Tignor, M., Allen, S. K., Boschung, J., Nauels, A., Xia, Y., Bex, V., and Midgley, P. M., Cambridge University Press, Cambridge, United Kingdom and New York, NY, USA, 1535 pp., 2013.

Jacobson, M. Z.: Strong radiative heating due to the mixing state of black carbon in atmospheric aerosols, Nature, 409, 695-697, 2001.

Khalizov, A. F., Zhang, R., Zhang, D., Xue, H., Pagels, J., and Mcmurry, P. H.: Formation of highly hygroscopic soot aerosols upon internal mixing with sulfuric acid vapor, J. Geophys. Res.Atmos., 114, D05208, https://doi.org/10.1029/2008JD010595, 2009a.

Khalizov, A. F., Xue, H., Wang, L., Zheng, J., and Zhang, R.: Enhanced Light Absorption and Scattering by Carbon Soot Aerosol Internally Mixed with Sulfuric Acid, J. Phys. Chem. A, 113, 1066-1074, 2009b.

Khatri, P., Takamura, T., Shimizu, A., and Sugimoto, N.: Observation of low single scattering albedo of aerosols in the downwind of the East Asian desert and urban areas during the inflow of dust aerosols, J. Geophys. Res.-Atmos., 119, 787-802, https://doi.org/10.1002/2013JD019961, 2014.

Kim, D.-H., Sohn, B. J., Nakajima, T., and Takamura, T.: Aerosol radiative forcing over east Asia determined from ground-based solar radiation measurements, J. Geophys. Res.-Atmos., 110, D10S22, https://doi.org/10.1029/2004JD004678, 2005.

Kok, J. F., Ridley, D. A., Zhou, Q., Miller, R. L., Zhao, C., Heald, C. L., Ward, D. S., Albani, S., and Haustein, K.: Smaller desert dust cooling effect estimated from analysis of dust size and abundance, Nat. Geosci., 10, 274-278, https://doi.org/10.1038/ngeo2912, 2017.

Li, G., Bei, N., Cao, J., Huang, R., Wu, J., Feng, T., Wang, Y., Liu, S., Zhang, Q., Tie, X., and Molina, L. T.: A possible pathway for rapid growth of sulfate during haze days in China, Atmos. Chem. Phys., 17, 3301-3316, https://doi.org/10.5194/acp17-3301-2017, 2017.

Li, J., Carlson, B. E., and Lacis, A. A.: Using singlescattering albedo spectral curvature to characterize East Asian aerosol mixtures, J. Geophys. Res.-Atmos., 120, 2037-2052, https://doi.org/10.1002/2014JD022433, 2015.

Li, W., Shao, L., Shi, Z., Chen, J., Yang, L., Yuan, Q., Yan, C., Zhang, X., Wang, Y., Sun, J., Zhang, Y., Shen, X., Wang, Z., and Wang, W.: Mixing state and hygroscopicity of dust and haze particles before leaving Asian continent, J. Geophys. Res.-Atmos., 119, 1044-1059, https://doi.org/10.1002/2013JD021003, 2014.
Li, Z., Lee, K.-H., Wang, Y., Xin, J., and Hao, W.-M.: First observation-based estimates of cloud-free aerosol radiative forcing across China, J. Geophys. Res.-Atmos., 115, D00K18, https://doi.org/10.1029/2009JD013306, 2010.

Li, Z., Guo, J., Ding, A., Liao, H., Liu, J., Sun, Y., Wang, T., Xue, H., Zhang, H., and Zhu, B.: Aerosol and Boundary-Layer Interactions and Impact on Air Quality, Natl. Sci. Rev., 4, 810-833, https://doi.org/10.1093/nsr/nwx117, 2017.

Logan, T., Xi, B., Dong, X., Li, Z., and Cribb, M.: Classification and investigation of Asian aerosol absorptive properties, Atmos. Chem. Phys., 13, 2253-2265, https://doi.org/10.5194/acp13-2253-2013, 2013.

Ma, Q., Liu, Y., Liu, C., Ma, J., and He, H.: A case study of Asian dust storm particles: Chemical composition, reactivity to $\mathrm{SO}_{2}$ and hygroscopic properties, J. Environ. Sci., 24, 62-71, 2012.

Noh, Y., Müller, D., Lee, H., Lee, K., Kim, K., Shin, S., and Kim, Y. J.: Estimation of radiative forcing by the dust and non-dust content in mixed East Asian pollution plumes on the basis of depolarization ratios measured with lidar, Atmos. Environ., 61, 221-231, 2012.

Noh, Y., Müller, D., Lee, K., Kim, K., Lee, K., Shimizu, A., Sano, I., and Park, C. B.: Depolarization ratios retrieved by AERONET sun-sky radiometer data and comparison to depolarization ratios measured with lidar, Atmos. Chem. Phys., 17, 6271-6290, https://doi.org/10.5194/acp-17-6271-2017, 2017.

Obregón, M. A., Pereira, S., Salgueiro, V., Costa, M. J., Silva, A. M., Serrano, A., and Bortoli, D.: Aerosol radiative effects during two desert dust events in August 2012 over the Southwestern Iberian Peninsula, Atmos. Res., 153, 404-415, 2015.

Pagels, J., Khalizov, A. F., McMurry, P. H., and Zhang, R. Y.: Processing of Soot by Controlled Sulphuric Acid and Water Condensation - Mass and Mobility Relationship, Aerosol Sci. Tech., 43, 629-640, 2009.

Pan, X., Uno, I., Wang, Z., Nishizawa, T., Sugimoto, N., Yamamoto, S., Kobayashi, H., Sun, Y., Fu, P., Tang, X., and Wang, Z.: Realtime observational evidence of changing Asian dust morphology with the mixing of heavy anthropogenic pollution, Sci. Rep., 7, 335, https://doi.org/10.1038/s41598-017-00444-w, 2017.

Peng, J., Hu, M., Guo, S., Du, Z., Zheng, J., Shang, D., Levy Zamora, M., Zeng, L., Shao, M., Wu, Y.-S., Zheng, J., Wang, Y., Glen, C. R., Collins, D. R., Molina, M. J., and Zhang, R.: Markedly enhanced absorption and direct radiative forcing of black carbon under polluted urban environments, P. Natl. Acad. Sci. USA, 113, 4266-4271, https://doi.org/10.1073/pnas.1602310113, 2016.

Qiu, C., Wang, L., Lal, V., Khalizov, A. F., and Zhang, R.: Heterogeneous reactions of alkylamines with ammonium sulfate and ammonium bisulfate, Environ. Sci. Technol., 45, 4748-4755, 2011.

Ramanathan, V. and Carmichael, G.: Global and regional climate changes due to black carbon, Nat. Geosci., 1, 221-227, 2008.

Ricchiazzi, P., Yang, S. R., Gautier, C., and Sowle, D.: SBDART: A research and teaching software tool for planeparallell radiative transfer in the Earth's atmosphere, B. Am. Meteorol. Soc., 79, 2101-2114, https://doi.org/10.1175/15200477(1998)079<2101:SARATS>2.0.CO;2, 1998.

Schuster, G. L., Dubovik, O., and Arola, A.: Remote sensing of soot carbon - Part 1: Distinguishing different absorbing aerosol species, Atmos. Chem. Phys., 16, 1565-1585, https://doi.org/10.5194/acp-16-1565-2016, 2016. 
Seinfeld, J. H., Carmichael, G. R., Arimoto, R., Conant, W. C., Brechtel, F. J., Bates, T. S., Cahill, T. A., Clarke, A. D., Doherty, S. J., Flatau, P. J., Huebert, B. J., Kim, J., Markowicz, K. M., Quinn, P. K., Russell, L. M., Russell, P. B., Shimizu, A., Shinozuka, Y., Song, C. H., Tang, Y., Uno, I., Vogelmann, A. M., Weber, R. J., Woo, J.-H., and Zhang, X. Y.: ACEASIA: Regional Climatic and Atmospheric Chemical Effects of Asian Dust and Pollution, B. Am. Meteorol. Soc., 85, 367-380, https://doi.org/10.1175/bams-85-3-367, 2004.

Stevens, B. and Bony, S.: What Are Climate Models Missing?, Science, 340, 1053-1054, https://doi.org/10.1126/science.1237554, 2013.

Sugimoto, N., Nishizawa, T., Shimizu, A., Matsui, I., and Kobayashi, H.: Detection of internally mixed Asian dust with air pollution aerosols using a polarization optical particle counter and a polarization-sensitive two-wavelength lidar, J. Quant. Spectrosc. Ra., 150, 107-113, 2015.

Taylor, M., Kazadzis, S., Amiridis, V., and Kahn, R. A.: Global aerosol mixtures and their multiyear and seasonal characteristics, Atmos. Environ., 116, 112-129, 2015.

Tian, P., Cao, X., Zhang, L., Wang, H., Shi, J., Huang, Z., Zhou, T., and Liu, H.: Observation and simulation study of atmospheric aerosol nonsphericity over the Loess Plateau in northwest China, Atmos. Environ., 117, 212-219, 2015.

Tian, P., Cao, X., Zhang, L., Sun, N., Sun, L., Logan, T., Shi, J., Wang, Y., Ji, Y., Lin, Y., Huang, Z., Zhou, T., Shi, Y., and Zhang, R.: Aerosol vertical distribution and optical properties over China from long-term satellite and ground-based remote sensing, Atmos. Chem. Phys., 17, 2509-2523, https://doi.org/10.5194/acp17-2509-2017, 2017.

Tian, P., Zhang, L., Cao, X., Sun, N., Mo, X., Liang, J., Li, X., Gao, X., and Zhang, B.: Enhanced Bottom-of-the-Atmosphere Cooling and Atmosphere Heating Efficiency by Mixed-Type Aerosols: A Classification Based on Aerosol Nonsphericity, J. Atmos. Sci., 75, 113-124, https://doi.org/10.1175/JAS-D-170019.1, 2018.

Twomey, S.: The Influence of Pollution on the Shortwave Albedo of Clouds, J. Atmos. Sci., 34, 1149-1152, 1977.

Tobo, Y., Zhang, D., Matsuki, A., and Iwasaka, Y.: Asian dust particles converted into aqueous droplets under remote marine atmospheric conditions, P. Natl. Acad. Sci. USA, 107, 17905-17910, https://doi.org/10.1073/pnas.1008235107, 2010.

Wang, G., Zhang, R., Gomez, M. E., Yang, L., Levy Zamora, M., Hu, M., Lin, Y., Peng, J., Guo, S., Meng, J., Li, J., Cheng, C., Hu, T., Ren, Y., Wang, Y., Gao, J., Cao, J., An, Z., Zhou, W., Li, G., Wang, J., Tian, P., Marrero-Ortiz, W., Secrest, J., Du, Z., Zheng, J., Shang, D., Zeng, L., Shao, M., Wang, W., Huang, Y., Wang, Y., Zhu, Y., Li, Y., Hu, J., Pan, B., Cai, L., Cheng, Y., Ji, Y., Zhang, F., Rosenfeld, D., Liss, P. S., Duce, R. A., Kolb, C. E., and Molina, M. J.: Persistent sulfate formation from London Fog to Chinese haze, P. Natl. Acad. Sci. USA, 113, 13630-13635, https://doi.org/10.1073/pnas.1616540113, 2016.

Wang, R., Tao, S., Wang, W., Liu, J., Shen, H., Shen, G., Wang, B., Liu, X., Li, W., Huang, Y., Zhang, Y., Lu, Y., Chen, H., Chen, Y., Wang, C., Zhu, D., Wang, X., Li, B., Liu, W., and Ma, J.: Black Carbon Emissions in China from 1949 to 2050, Environ. Sci. Technol., 46, 7595-7603, https://doi.org/10.1021/es3003684, 2012.
Wang, Y., Wan, Q., Meng, W., Liao, F., Tan, H., and Zhang, R.: Long-term impacts of aerosols on precipitation and lightning over the Pearl River Delta megacity area in China, Atmos. Chem. Phys., 11, 12421-12436, https://doi.org/10.5194/acp-11-124212011, 2011.

Wang, Z., Pan, X., Uno, I., Li, J., Wang, Z., Chen, X., Fu, P., Yang, T., Kobayashi, H., Shimizu, A., Sugimoto, N., and Yamamoto, S.: Significant impacts of heterogeneous reactions on the chemical composition and mixing state of dust particles: A case study during dust events over northern China, Atmos. Environ., 159, 83-91, 2017.

Wu, G., Li, Z., Fu, C., Zhang, X., Zhang, R., Zhang, R., Zhou, T., Li, J., Li, J., Zhou, D., Wu, L., Zhou, L., He, B., and Huang, R.: Advances in studying interactions between aerosols and monsoon in China, Sci. China Earth Sci., 59, 1-16, https://doi.org/10.1007/s11430-015-5198-z, 2016.

Wu, Y., Zhu, J., Che, H., Xia, X., and Zhang, R.: Column-integrated aerosol optical properties and direct radiative forcing based on sun photometer measurements at a semi-arid rural site in Northeast China, Atmos. Res., 157, 56-65, 2015.

Xin, J., Gong, C., Wang, S., and Wang, Y.: Aerosol direct radiative forcing in desert and semi-desert regions of northwestern China, Atmos. Res., 171, 56-65, 2016.

Xue, H., Khalizov, A. F., Wang, L., Zheng, J., and Zhang, R.: Effects of dicarboxylic acid coating on the optical properties of soot, Phys. Chem. Chem. Phys., 11, 7869-7875, 2009.

Yu, X., Lü, R., Kumar, K. R., Ma, J., Zhang, Q., Jiang, Y., Kang, N., Yang, S., Wang, J., and Li, M.: Dust aerosol properties and radiative forcing observed in spring during 2001-2014 over urban Beijing, China, Environ. Sci. Pollut. R., 23, 15432-15442, https://doi.org/10.1007/s11356-016-6727-9, 2016.

Zhang, D. and Zhang, R.: Laboratory Investigation of Heterogeneous Interaction of Sulfuric Acid with Soot, Environ. Sci. Technol., 39, 5722-5728, https://doi.org/10.1021/es050372d, 2005.

Zhang, M., Wang, L., Gong, W., Ma, Y., and Liu, B.: Aerosol Optical Properties and Direct Radiative Effects over Central China, Remote Sens., 9, 997, https://doi.org/10.3390/rs9100997, 2017.

Zhang, R., Mingtaun Leu, A., and Keyser, L. F.: Heterogeneous Chemistry of HONO on Liquid Sulfuric Acid:? A New Mechanism of Chlorine Activation on Stratospheric Sulfate Aerosols, J. Phys. Chem., 100, 339-345, 1996.

Zhang, R., Khalizov, A. F., Pagels, J., Zhang, D., Xue, H., and McMurry, P. H.: Variability in morphology, hygroscopicity, and optical properties of soot aerosols during atmospheric processing, P. Natl. Acad. Sci. USA, 105, 10291-10296, https://doi.org/10.1073/pnas.0804860105, 2008.

Zhang, R., Wang, G., Guo, S., Zamora, M. L., Ying, Q., Lin, Y., Wang, W., Hu, M., and Wang, Y.: Formation of Urban Fine Particulate Matter, Chem. Rev., 115, 3803-3855, https://doi.org/10.1021/acs.chemrev.5b00067, 2015.

Zhao, C., Tie, X., and Lin, Y.: A possible positive feedback of reduction of precipitation and increase in aerosols over eastern central China, Geophys. Res. Lett., 33, L11814, https://doi.org/10.1029/2006GL025959, 2006. 